\title{
Luis Oyarzún
}

\section{Gabriela Mistral (1)}

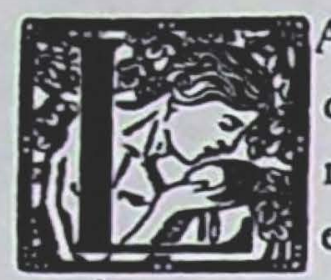

A IMAGEN de un rostro noble, inmóvil al fin, después de una vida en que el fuego más puro lo animara, llena hoy nuestro corazón. Ya no será para siempre sino esa cosa impalpable, una imagen. El ser apasionado que pasó entre nosotros como una figura casi divina a fuerza de humanidad profunda, conoce ahora lo que no conocemos y, sin embargo, no nos sentimos sin él. Sentimos que él vela por nosotros, que su mirada desciende amorosamente hacia su pueblo y que, con la fuerza misma de su ausencia, ella nos une. Muchas generaciones recordarán este instante solemne, esta despedida, y sentirán con nosotros la congoja de ver partir a quien fuera un símbolo viviente de nuestra tierra. Los que hoy son niños contarán a sus hijos que vieron pasar un día a su lado, con recogimiento y tristeza, a una mujer que amó a la vida y que no temió a la muerte, a una mujer que elevó nuestra condición humana ante los demás y ante nosotros mismos.

Algunos poetas nos deleitan, otros nos deslumbran, otros nos desconciertan hasta enriquecernos con una visión nueva de las cosas. $\mathrm{Y}$ hay algunos también, muy pocos, que, por hacerse carne y sangre

(1) Discurso pronunciado en los funerales de Gabricla Mistral, a nombre de los escritores chilenos. 
en nosotros, nos acompañan siempre y en verdad no sólo nos transforman. Hacen mucho más. Excitan en nosotros lo más vivo y al transmitirnos su fulgor, nos inflaman y nos dan vida nueva.

Por épocas enteras, nuestro mundo americano pareció a muchos deshabitado de espíritu. Sin grandes libros, sin monumentos formadores, sin las viejas dulzuras de la civilización, estos países pudieron ser vistos como desiertos para el alma. Hasta que de pronto una forma nueva de mirar descubre allí mismo, entre montañas, arenales, árboles y costas, la presencia de unos seres que siempre estuvieron ahí, pero que no fueron vistos. Aquello mismo que nos rodeaba no había sido conocido porque no era amado y sólo esa quemante pasión amorosa que es la poesía fue capaz de descubrir, junto con su existencia, su virtud. Estas almas de poder visionario fundan el mundo. Sólo ellas le confieren precio humano. Sólo ellas lo abren a las posibilidades sin fin de la invención del espíritu. Sin esa poesía, la tierra sería inhóspita como un astro muerto y nada de lo humano podría desplegarse. Demos gracias, por eso, a esta mujer que vió, como a sravés de una hoguera nunca extinguida, tanta cosa arcaica e ignorada, tanta cosa que la tierra y sus gentes mostraban, esperando que al fin alguien la viera no sólo para sí, esperando a eso que un día ve, ebrio de amor, por todos.

Cada uno de nosotros vive rodeado de cosas que piden ser vistas. Cosas familiares, humildes, que lo son todo para muchos: el pan, el agua, la casa, los frutos de la tierra, los hijos, y que son poca cosa para muchos otros, traídos y llevados por la complicación del mundo. En medio de la infinitud, toda vida humana es modesta, insignificante. Pero ciertos hombres poseen la virtud de hallar en nuestra pequeñez y hasta en los objetos desdeñables un halo de eternidad. Ciertos ojos son capaces de descubrir aquello que une al utensilio humano o al alimento del cuerpo con los deseos inextinguibles que sólo el alma engendra. Esos ojos santifican la vida y elevan, aun a los más desvalidos, por encima de toda injusticia, a una dignidad que une a los hombres, que dulcifica al fuerte $y$ da valor e inspiración al débil. 
Los versos de ciertos poetas expresan aquella necesidad que mueve a los hombres a descubrirse entre sí y amarse. A cierta profundidad de la vida, el corazón humano olvida sus límites y sus resentimientos y tiembla sólo para expresar, en la transparencia del lenguaje, aquello que es tan esencial a la existencia como el aire; el amor descubridor del mundo, el que exalta y consuela, el amor que perdona, el que, transformado en ojos, ve y vuela hasta las últimas distancias. A menudo se olvida que para la más insignificante florecilla es necesario amar también la eternidad. Entre los extremos, la vida humana pugna por hacerse fecunda y lo es, en medio de sus conflictos, sólo en la medida en que podamos, siquiera un instante, como esta mujer combatida por sí misma, abrir las manos y recibir lo que nos es donado. Porque llegó hasta lo más hondo de sí, pudo Gabriela Mistral amar tanto a los seres y olvidarse, en ese privilegiado trance, de sí. En esta época en que el amor y la solidaridad entre los hombres se han convertido en oratoria, ese ejercicio interior que ella nos lega es un ejemplo. Más que un ejemplo, un destino.

Pues la poetisa que hoy lloramos fue una maestra a la manera en que lo son las madres, por vocación natural, por necesidad y amor. Entendió su oficio como el de la Cuenta Mundos que ella cantara y en sus canciones nos reveló, como en un viejo libro de horas, cosas e historias de cosas que son y serán una suerte de retrato de la tierra que nos rodea dulcificada por una ternura que nos hace mejores. Sintió Gabriela Mistral en toda su crudeza la fuerza dura de nuestra geografía y aún de nuestra historia, y ella misma, criatura de este continente, poseyó esa fuerza, como una estatua de piedra alzada en medio del paisaje. Mas, vio también cómo es posible extraer del yermo la fuente de agua pura que lo hace fértil.

El poeta llega a suprimir las distancias que aislan a los hombres. Aun sin proponérselo, él promueve esa comunicación entre los seres que la vida, hasta en sus momentos más altos, nos niega. Gabriela Mistral nos hizo sentir desde niños nuestro parentesco con tanta cosa de nuestra tierra que sin ella nos hubiera sido extraña. No sólo el viento, las selvas y las serranías afiladas de Chile y de América. Tam- 
bién el sufrimiento y la pasión, las alegrías y los juegos de nuestros hermanos, y sobre todo nos dio, sonriente e infinitamente triste, el torbellino de sí misma. Nos dio esa cosa difícil entre todas: nos dio acceso a la soledad entrañable del ser que vive, triunfante a veces, a veces derrotado, en la experiencia siempre nueva, en la experiencia eterna de vivir. Ahora, ella nos deja y sentimos mucho más que la pérdida de algo precioso del mundo. Sentimos que se cierran para siempre unos ojos que nos abrían al mundo y nos lo daban, algo de nuestros propios ojos. ¿Quién habrá de conquistar, a fuerza de soledad, tanta comunicación gozosa con cielos, bestezuelas y pájaros? ¿Quién hablará en nombre de las viejas madres, quién nos dirá mejor lo que ella nunca tuvo? Hay otros, vendrán otros, pero son y serán distintos. No fue una santa, no fue un ángel. Fue, aun en medio de la gloria del mundo, una mujer que nos confió lo que veía, con tal intensidad de pasión que no podía sino excitar la nuestra, y ahora ella nos ve en torno suyo sin otra cosa que ese mismo corazón amante que alguna vez, cuando hemos sido despojados de todo, nos define.

Este apasionado homenaje es la comprobación de algo que la nación chilena, probablemente, no sabía de sí misma: su profundo humanismo. Pues en esta mujer que despedimos, reconocemos un bien perecedero y eterno, que une muchas diferentes virtudes. Reconocemos el valor de lo humano, realizado en un símbolo que hasta ayer fuera una criatura real, una mujer que conoció la desesperación y la pasión, el abatimiento y la alegría, el amor y la inteligencia, el desvelo y el sueño. Una mujer muy sola que sintió desde la más honda soledad no sólo su propio desvarío, sino también el dolor del prójimo. Desde lejos, desde mucho más lejos que todas las distancias geográficas, desde el último apartamiento, ella salió de sí y, dándonos el fondo de su alma, nos alentó a seguir en busca de ese amor que acerca a los hombres y mueve a las esferas.

Hoy se cree demasiado en las ideas y poco en las personas. Pero aquí tenemos el ejemplo, más vivo que las ideologías, de una pasión humana real, el ejemplo de un ser que, con todos los accidentes de 
la condición humana, amó a la tierra y amó a los hombres, olvidándose muchas veces de sí. Algunos tratan de legitimar su poesía, de justificarla recordando opiniones dispersas. Pero ella, falible como nosotros, tuvo la fortaleza de ser dura y tierna, una persona viviente, tan rica de substancia personal que ninguna justificación podría serle necesaria. Existió, simplemente, y por eso, porque fue como la conocimos, a ella demos gracias, porque un ser como ella es más rico que todas las ideas.

Hablo en este instante en nombre de sus compañeros escritores. Hablo como muchos otros hablarían, y con menos títulos que muchos, en virtud de ese amor que ella nos diera y que tuvo eco en tantos. Le agradecemos, sencillamente, la grandeza que trajo a nuestra literatura.

Gabriela Mistral amó hasta el extremo de la pasión a la tierra con todas sus criaturas. Jamás perdió la capacidad de ver y descubrir con tanta vehemencia que los seres se le entregaban, rendían su secreto bajo el magnetismo de esos ojos tranquilos. La poesía surgía en ella como la expresión de algo mucho más hondo que el sentimiento de la belleza. Brotaba de su amor por la tierra, de su conocimiento entrañable del dolor, de su piedad por todo lo que pide consuelo, de su íntegra humanidad. Por eso, sin quererlo expresamente, fue una maestra de vida, uno de esos seres privilegiados que irradian poder espiritual y transfiguran lo que tocan sus manos. Nada de lo nuestro le fue ajeno y menos ajeno que nada le fue el impulso irresistible de elevar la vida, la pasión de servir. Ella logró convertir en dádiva continua el genio indómito que se agitaba en ella. Sus sentidos finamente vibrantes la pusieron en comunicación apasionada, como de madre a hijo, con nuestra tierra americana y sus pueblos. No es extraño, entonces, que los más desvalidos, los seres más próximos a la tierra, los que sufren sus durezas y viven de su fecundidad, fueran sus predilectos. No es extraño que esos mismos hombres y mujeres humildes le devolvieran su amor con reverencia. Recuerdo haber visto cómo se le acercaban en los campos, interrumpiendo sus trabajos, con mirada honda y tierna, los hombres que labraban la 
tierra, esa tierra que misteriosamente era suya, la tierra a que ella vuelve hoy, semilla casi impalpable, para siempre.

En verdad, no nos deja. ¡Cómo podría dejarnos quien nos dio tanto! Está con nosotros y estará con nuestros hijos. Sus palabras modificaron nuestro idioma y cambiaron el orden de nuestro corazón. Discretamente, en sordina, digamos, en este último instante, con ella:

Estemos juntos los reencontrados,

Hasta que seamos otra vez uno

y nuestro día haya acabado... 